\title{
Implementing Mobile Learning Within Personal Learning Environments: A Study of Two Online Courses \\ José Bidarra1 ${ }^{1,3}$ and Nuno Sousa ${ }^{1,2}$ \\ ${ }^{1}$ Universidade Aberta, ${ }^{2}$ INESC-Coimbra, ${ }^{3} \mathrm{CIAC}$-Universidade do Algarve, Portugal
}

\begin{abstract}
This article presents a case-study of two distance learning courses, in order to address the question of universal adoption of mobile devices and applications by students, and the impact of these devices in personal learning environments (PLEs). First, a critical discussion of the value of these concepts in the current technological context was carried out, followed by an analysis of their impact on educational use, based on data collected in online courses on physics and statistics at Universidade Aberta, the Portuguese Open University. The results indicated that all students have adopted mobile learning, and the make-up of an individual's PLE depends more on the learning resources available rather than on gender or age. These findings can help provide more efficient ways to implement learning by connecting current social needs to learners' mobile PLEs, particularly when flexibility of time and space are of utmost importance. Further studies at the Portuguese Open University will address a larger and more balanced sample of students across more course units.
\end{abstract}

Keywords: mobile learning, personal learning environment, social media, open university 


\section{Introduction}

The current context of open and distance learning is fertile ground for the re-conception of education as a mobile and flexible interaction with many stakeholders. It has changed the traditional view of classroom instruction often replicated in online teaching, and that of education as the transmission of knowledge bound by the restrictions set by a fixed curriculum. Within this context, education has become an on-going process of learning through continued inquiry, sharing, and cooperation-in the various circumstances, roles, and settings in which an individual plays a part (e.g., school, work, leisure, family/private contexts). Social media can be a useful tool in facilitating offline relationships and maintaining ties (Thomas, Orme, \& Kerrigan, 2020). Using social media to support distance education augments the power of learning communities with the benefits of using technology to support student engagement. However, this is a difficult process to scrutinize because it involves many variables; it is challenging to acquire an accurate sense of the different aspects of learning that are being evaluated (Lai \& Bower, 2019). Concerns have been raised regarding academic distraction within personal learning environments (PLEs), more specifically the overuse of social media and the Internet for entertainment, with a negative effect on students' academic success (Feng, Wong, Wong, \& Hossain, 2019).

Nevertheless, there is a perception that students of the so-called PlayStation generation tend to react better to learning based on interactive and dynamic features, with the possibility of consulting not only textbooks but also other media with links to online databases (Kearney, 2016). On the other hand, many students use mobile technologies for both personal use and for studying in a collaborative way. Most learners consider them as key components of the world in which they live and are more willing to engage in educational processes when the results they are to attain are presented as networked multimedia activities (Kukulska-Hulme, 2007). In fact, these users have created their own communications environment and are already telling their own stories on YouTube, on Facebook, on Instagram, and on many other social media, based on their perceived usefulness (Gómez-Ramirez, Valencia-Arias, \& Duque, 2019).

Teachers and colleges can also use these new emerging technologies to foster learning, creativity, and students' enthusiasm. New technologies are relevant in areas related to the school curriculum, but also in other areas of knowledge, particularly in open and distance education courses where student isolation can be an obstacle (Bidarra, Figueiredo, \& Natálio, 2015). Thus, the main motivation for this research was to ascertain the universal use of mobile learning in open and distance learning, and how it shapes students' PLEs. Therefore, this study posed the following research questions:

1. To what degree is mobile learning currently being adopted by the students at Universidade Aberta? Are there individual factors that significantly determine its adoption by these students?

2. How do mobile learning tools influence students' PLEs? Do the individual factors have an impact on this influence?

This article starts with a review of the relevant literature concerning the use of mobile devices and applications by students, following up on evidence that shows a change in paradigm where the control of learning shifts from the institution towards the student. Although the terms mobile learning and personal learning environment are often used in the context of online learning, institutions do not usually see a clear benefit in the association of students' mobile and PLE factors at the course level. Some authors have stated that mobile learning has actually been implemented more in the spirit of a 
virtual learning environment (VLE) than a PLE, and that there remains a great deal of unexplored ground in the area of mobile PLE systems (Chen, Millard, \& Wills, 2008). This has not changed much in the last decade; perhaps a very promising institutional aim would be to provide an online learning environment that combines structured learning with the flexibility and personalization that a mobile PLE offers. Our goal was to fill that gap by investigating students' actual use of mobile devices and PLEs in the current technological context, based on data collected in two online courses (physics and statistics) at Universidade Aberta, the Portuguese Open University.

\section{Integrating Mobile Learning into PLEs}

Research on mobile learning has covered a variety of themes, but the most common has typically concentrated on enabling applications and systems (Krull \& Duart, 2017). An increasing number of studies have focused on the use and affordances of smartphones and tablets (e.g., the use of specific apps) rather than the instructional design of educational content. Another relevant factor, perhaps the most significant change so far, has been the emergence of social media, generating huge amounts of data and connecting users across the world. This has implications for students' mobile PLEs as open and distance teaching universities need to encourage socialization by means of digital media. Often these integrate mobile learning with social networking, gamification, and augmented reality. But a more in-depth research is needed to show how to reconcile mobile hardware and software, lesson content, teaching methods, and educational goals (Sung, Chang, \& Liu, 2016).

In the area of open and distance learning, the development of PLEs has been identified with a specific field of research (Johnson \& Liber, 2008) covering several perspectives that may include technological and social aspects (e.g., open software, social networks, virtual environments). Essentially, a PLE is a mix of learning resources that may be used by students in the context of learning a specific subject (van Harmelen, 2008). The body of research on PLE started around 2005 with research disseminated by authors such as S. Wilson, M. van Harmelen, G. Atwell, S. Downes, and G. Siemens (Fiedler \& Väljataga, 2013). According to Attwell, Bimrose, and Brown (2008) "a PLE should be based on a set of tools to allow personal access to resources from multiple sources and to support knowledge creation and communication" (p. 82). One typical aspect, but also a problem for researchers, is that PLEs integrate people, tools, communities, and resources in a very loose kind of way (Wilson, 2008).

Despite the potential benefits contained in a PLE, Dabbagh and Kitsantas (2012) recognized that not all students possess knowledge management abilities and the necessary self-regulatory skills to effectively make the most of it. This is why the demographic variables of gender and age were used as statistical factors in this study. There is also a relevant learning curve associated with the development of a learning environment that works for the student. So, from an educational perspective, there is a need to support online learners and help them model their learning environments in the context of the courses they are studying (Fiedler \& Väljataga, 2013). This opens the door to mobile learning solutions, which are often described as supporting informal learning (Sharples, Corlett, \& Westmancott, 2002).

If the popularity of mobile devices (e.g., smartphones and tablets) is considered, one realizes that informal learning has been a valid paradigm for educational technology since the beginning of this century. Traxel (2009) defined learning with mobile devices simply as the kind of learning that is supported by a portable or mobile device, encouraging learning through the ease of access to information and the ability to transport and manage very diverse content (e.g., text, image, audio, video, 
animation). Integrating mobile devices into the pedagogical models used in open and distance learning is a most desirable goal, and follows an active learning perspective (Prince, 2004). This is of utmost importance to open universities, such as Universidade Aberta, who must rely on digital technology to support global reach, social acceptance, and assure high standards of quality in online teaching and learning (Cross, Sharples, Healing, \& Ellis, 2019).

\section{Towards Seamless and Ubiquitous Learning}

In the last decade, developments in the sophistication of mobile devices which, integrated with seamless networked media applications, have provided novel approaches to online learning that have enhanced the everyday use of learning management systems (García-Peñalvo \& Conde, 2015). Mobile devices and PLEs give students the power to access, aggregate, configure, and manipulate digital artifacts in the context of their learning experiences. The advantages of mobile learning tools comprise the ability to connect anytime and anywhere to online resources, such as electronic books (e-books) and apps, bringing this possibility to the realm of learning environments. But while mobile devices can improve educational effects, the actual impact of mobile learning programs needs to be enhanced by longer intervention durations, closer integration of technology and the curriculum, and further assessment of higher-level skills (Sung et al., 2016).

A comprehensive study on mobile seamless learning by Wong and Looi (2011) suggested that

learners need to be engaged in an enculturation process to transform their existing epistemological beliefs, attitudes, and methods of learning. Therefore, at the early stage of learners' engagement with mobile devices, teachers need to model the seamless learning process by gradually and systematically incorporating mobile learning activities into the formal curriculum. (p. 5).

Another study (Park, 2011) also supported the advantages of ubiquitous learning and discussed the features and pedagogical potential of mobile learning, anytime, anywhere. More recently, other research has emerged, and correlated the ICT skills of today's students and their choice of PLE, including mobile learning (Schmid \& Petko, 2019). This new perspective considers the connection among PLE, social media, and self-regulated learning as a multilayered approach to the use of digital technologies for personalized learning. Furthermore, the cross-cultural design of technology can help to identify culturally relevant areas such as attitudes towards informal and collaborative learning, while recognizing the local context for content delivery. It may also support the development of a sound user experience of mobile learning in different learning contexts (Vainio \& Walsh, 2017).

However, even if learning with mobile technology empowers learner-centered educational decisions towards the construction of PLEs, there are issues of gender, age, and access that may be an obstacle to the acceptance of mobile learning. The ways in which different students integrate these instruments into their PLEs has been the focus of more specific research (Labach, 2011). Of course, there are also myths and misperceptions related to mobile learning (Brown \& Mbati, 2015), but in this article the focus is on empirical knowledge from specific distance learning courses.

This present study sought to ascertain how universal (i.e., how widespread) were the previous literature findings, by looking at current empirical data. In a sense, it tried to answer the question of whether 
those findings apply to all distance learning students. Also, it sought out individual factors which may influence, and to what degree, the conclusions highlighted in this literature review, namely, how mobile learning has shaped students' PLEs. To our best knowledge, this was the first attempt to do so in a quantitative manner.

\section{Empirical Evidence From Two Courses}

More than 10 years have passed since Universidade Aberta's virtual pedagogical model for distance education was laid out in detail (Pereira, Quintas-Mendes, Morgado, Amante, \& Bidarra, 2008). This essential teaching framework, which still guides the institution today, has put an almost exclusive emphasis on the deployment of e-learning resources based on a VLE. At the time of its inception, emerging concepts such as mobile learning or ubiquitous learning were not considered. Today, in an ever-expanding networked context, an online pedagogical strategy is still key, but there is no point in restricting the options for students, the faculty or the institution.

A pedagogical framework for mobile learning has been proposed by Park (2011), to enable instructional designers and individual learners to incorporate mobile technologies into their teaching and learning effectively. This could be easily merged with the virtual pedagogical model for distance education used by Universidade Aberta, thus adopting a transactional distance view, and adding a new dimension to reflect the characteristics of mobile technologies that support both individual and social aspects of learning. This approach followed up on Cochrane (2010), who highlighted that the critical success factors are still

the pedagogical integration of the technology into the course assessment, lecturer modelling of the pedagogical use of the tools, the need for regular formative feedback from lecturers to students, and the appropriate choice of mobile devices and software to support the pedagogical model underlying the course. (p. 133)

Currently, the pedagogical situation has changed little, but the mobile devices and software have improved, and a new global integration with social media and digital tools has emerged. This has made it possible to create effective personal learning environments suitable for mobility.

Bearing in mind that it is desirable to enhance the seamless experience of students by integrating mobile devices into teaching methods, this research was designed to ascertain the actual situation concerning the integration of mobile PLEs in two online courses at Universidade Aberta, one on introductory physics and the other on basic statistics. The aim of the empirical study was to find out how students in those courses used mobile devices during their learning processes, including online interaction, social communications, and learning activities. The two courses were selected because they were part of the core curriculum and science-oriented, and so they made use of a wider range of the learning resources available, both within and outside the institution. Also, the courses encompassed two major areas of knowledge; the physics course was part of the syllabus of two science degrees (computer science and environmental science) and the statistics course was part of the syllabus of a social science degree.

Ultimately, we wanted to probe the status of student use of mobile devices integrated within PLEs and find ways in which the learning tools could be adopted and integrated within activities. Data was gathered through an online survey, over the course of three academic years (2015-2018), aimed at 
students in each course unit (CU), and collected the following quantitative data:

1. Students were profiled according to three individual factors, namely, gender, age, and course unit type, to ascertain whether the degree of mobile technology adoption depended on these factors;

2. To establish a PLE structure, the different apps and tools used in the learning context were surveyed for adoption and type of use (e.g., activities, communication, collaboration, sharing). The influence of individual factors was also tested for;

3. The amount of time students spent with the courses was established, in order to discriminate different kinds of learning interaction, and how this time compared with the time spent in social networking and personal messaging, in an academic context.

\section{Sample and Methods}

A researcher-designed online questionnaire was used to collect data from the students in the two courses. Because the eligible population was small, the questionnaire was made short and straightforward, in order to maximize the response rate while achieving the study objectives. Face validation was carried out by the authors and, where deemed relevant, a clarification text was inserted next to the questions. A total of 164 responses was obtained from students who volunteered to participate, and a search for eventual outliers was carried out, though none were found. Table 1 summarizes sample data, discriminated by individual factors.

Table 1

Characteristics of the Sample

\begin{tabular}{|c|c|c|c|c|c|}
\hline \multirow[b]{3}{*}{ Age } & \multirow{2}{*}{\multicolumn{2}{|c|}{$\begin{array}{c}\text { Physics }(n=101) \\
\text { Gender }\end{array}$}} & \multirow{2}{*}{\multicolumn{2}{|c|}{$\begin{array}{c}\text { Statistics }(n=63) \\
\text { Gender }\end{array}$}} & \multirow[b]{3}{*}{ Total } \\
\hline & & & & & \\
\hline & Male & Female & Male & Female & \\
\hline Less than 35 years & 15 & 5 & 2 & 11 & 33 \\
\hline 35 to 44 years & 37 & 13 & 7 & 13 & 70 \\
\hline 45 to 54 years & 14 & 11 & 5 & 18 & 48 \\
\hline More than 55 years & 2 & 4 & 2 & 5 & 13 \\
\hline Total & 68 & 33 & 16 & 47 & 164 \\
\hline
\end{tabular}

The individual factors, known as predictors in statistical language, were tested for statistical significance using binomial and ordinal logistic regressions, depending on the nature of the dependent variable. Spearman correlations were also obtained where relevant. All calculations were carried out using the $\mathrm{R}$ statistical software and logistic regression packages.

Logistic regression was chosen because it is the adequate statistical method to model situations where the dependent variable is discrete in nature (e.g., yes or no). Logistic regression can be used with multiple categorical predictors, which was the case in this research. See Niu (2020) for a review of applying this method to educational research, and refer to Alzen, Langdon and Otero (2018) for a recent example.

Both courses included Moodle discussion forums, short videos, e-book exercises, and solutions as pedagogical resources, and all were accessible from mobile devices. Other interactive resources were under development but were not yet available for students at the time of the survey. 


\section{Results}

Analysis number one. Concerning the analysis to evaluate mobile technology adoption by students and what factors influenced it, data showed a clear adoption of mobile learning tools, with 126 students out of 164 (77\%) stating they used some kind of mobile device in their study. Thus, the answer to this first part of research question 1 was that the degree of adoption was very high.

As for trends in mobile learning adoption, Table 2 summarizes the statistical findings with respect to the influence of individual factors.

Table 2

Significance of the Use of Mobile Devices in Course Study

\begin{tabular}{|c|c|c|c|c|c|}
\hline \multirow[b]{2}{*}{ Variable } & \multicolumn{5}{|c|}{ Analysis of deviance table } \\
\hline & $D f$ & Deviance & Residual Df & Resid. deviance & $\operatorname{Pr}(>$ chi $)$ \\
\hline NULL & & & 163 & 177.56 & \\
\hline Gender & 1 & 0.0395 & 162 & 177.52 & 0.8425 \\
\hline Age & 3 & 4.0117 & 159 & 173.50 & 0.2602 \\
\hline \multirow[t]{3}{*}{ CU type } & 1 & 0.0389 & 158 & 173.47 & 0.8436 \\
\hline & \multicolumn{5}{|c|}{ Coefficients } \\
\hline & & Estimate & Std. error & $Z$ value & $\operatorname{Pr}(>|z|)$ \\
\hline Intercept & & 1.35018 & 0.50466 & 2.675 & $0.00746^{* * *}$ \\
\hline Gender: male & & -0.16956 & 0.41781 & -0.406 & 0.68487 \\
\hline Age 35 to 44 years & & -0.08541 & 0.51498 & -0.166 & 0.86828 \\
\hline Age 45 to 54 years & & 0.14161 & 0.56639 & 0.250 & 0.80257 \\
\hline Age 55 plus years & & -1.18224 & 0.70698 & -1.672 & $0.09448 *$ \\
\hline CU type physics & & 0.08372 & 0.42392 & 0.198 & 0.84343 \\
\hline
\end{tabular}

Note. Dependent variable output use_of_mobile: No $(n=38)$, Yes $(n=126)$.

${ }^{* * * *} p<0.01,{ }^{*} p<0.1$.

Table 2 reads as follows. In a binary logistic regression, a base scenario is characterized by a particular level of the factors, in this case, gender, age, and CU type. In Table 2, the scenario, defined by default by the software, was of a female, statistics student, under 35 years old with a log-odds of responding "yes" to the question "Do you use mobile devices in your physics/statistics study?" of 1.35018 (probability: $1 /[1+\exp (-1.35018)]=79 \%)$. Changes to the base scenario yield changes in the log-odds. For instance, if the student were female, statistics course, but over 55 years old, the log-odds would drop to $1.35018-1.18224=0.16794(54 \%)$. The analysis of deviance p-values $[\operatorname{Pr}(>$ Chi)] indicate whether a factor was, or not, statistically significant in the output of the dependent variable. Low p-values $(<$ 0.01 or $1 \%$ ) indicate that the factor clearly influenced the output variable (Yes or No), whereas high pvalues (> 0.10 or $10 \%$ ) indicate it did not (i.e., different levels of that factor did not significantly influence the odds of replying Yes or No). P-values between these figures are in a grey area and mean that there was some statistical evidence that the factor influenced the output, but that evidence was not clear-cut. The coefficients p-values $[\operatorname{Pr}(>|z|)]$ indicate whether a particular level of the factor was, or not, statistically significant. The estimate column indicates by how much the log-odds shift towards (away if negative) a Yes in the output variable. Usually, if a factor is not significant (i.e., if it has high pvalues) its associated coefficients show high p-values as well. In Table 2, the dots and asterisks help identify p-value range without having to look at the explicit figures (see note to Table 2). Other columns show intermediate data from the R software. 
In the particular case of use of mobile devices, the deviance table shows that the tendency for using these devices was spread evenly across the field, regardless of age, gender, or CU type. In fact, the intercept (i.e., base log-odds of having Yes as survey answer) was a good enough predictor and the only one with clear statistical significance. There was an extremely slight tendency for students above the age of 55 to reject this kind of learning ( $p=9.4 \%$ ), but this was too weak a hint to have called it clearcut.

An analysis of whether students prefer only mobile learning was also carried out, yielding a rate of about $50 \%$ (No, $n=83$; Yes, $n=81$ ); the corresponding binomial regression found no influence by the factors (all p-values $>10 \%$, including intercept).

Given the growing market trend of mobile device sales and their technological possibilities-ownership of mobile phones in Portugal was near 100\% in 2018 (ANACOM, 2019)-the authors expect the already high degree of adoption of mobile learning to rise even further, possibly to a rate very near $100 \%$.

Analysis number two. The second line of analysis required determining what specific apps and tools had been adopted in the learning context and whether this depended on the gender, age, and CU type factors. Various output variables were considered; the full list is shown in Table 3, together with the observed degree of penetration of the various apps and tools as well as theoretical estimates from the binary logistic regression models (i.e., intercept log-odds, transformed into probabilities).

Table 3

Use of Apps and Tools in an Academic Context

\begin{tabular}{lcc}
\hline App or tool & Empirical Yes & Logistic regression odds for Yes \\
\hline Use of Facebook & $70 \%$ & $77 \%$ \\
Use of social media (any type) & $77 \%$ & $76 \%$ \\
Messaging on Facebook* & $52 \%$ & $80 \%$ \\
Messaging (any type) & $70 \%$ & $85 \%$ \\
Files, video or image sharing & $79 \%$ & $76 \%$ \\
Use of academic apps & $67 \%$ & $64 \%$ \\
Use of e-books* & $82 \%$ & $82 \%$ \\
Use of Wikipedia* & $72 \%$ & $55 \%$ \\
Use of productivity suites & $95 \%$ & $82 \%$ \\
Average & $74 \%$ & $75 \%$ \\
\hline Note. Asterisk (*) indicates that individual factors had significant influence on the output variable.
\end{tabular}

Both the empirical and model-estimated percentages indicated a high acceptance rate for all apps and tools tested, reinforcing evidence of a shift from institution-based resources towards student-based resources. This clearly showed a trend of learners looking for study apps and tools on their own, thus moving beyond teacher-prescribed resources.

The binary logistic regression results yielded significant influence of individual factors for only three of the output variables, namely use of Facebook messaging, e-books, and Wikipedia. For the remaining variables, only the intercepts were statistically significant, and all pointed in the Yes direction. Absence of significant coefficients for the factors indicated, just as it did for the first analysis, that students' PLE are relatively uniform across the student population. The discrepancies between observed and logistic odds are of technical origin (i.e., variance-minimization procedures) and appeared to be due to small 
sample size. These are expected to decrease if a larger sample is considered.

As for the output variables with significant coefficients, deviance and coefficient tables are shown in Tables 4, 5, and 6. Table 4 presents the results for Facebook messaging.

Table 4

Significance of Using Facebook Messaging

\begin{tabular}{|c|c|c|c|c|c|}
\hline \multirow[b]{2}{*}{ Variable } & \multicolumn{4}{|c|}{ Analysis of deviance table } & \multirow[b]{2}{*}{$\operatorname{Pr}(>$ chi $)$} \\
\hline & $\overline{D f}$ & Deviance & Residual Df & Residual deviance & \\
\hline NULL & & & 163 & 227.13 & \\
\hline Gender & 1 & 13.1938 & 162 & 213.95 & $0.0002809 * * * *$ \\
\hline Age & 3 & 1.8359 & 159 & 212.10 & 0.6071586 \\
\hline CU type & 1 & 3.1422 & 158 & 208.96 & 0.0762918 \\
\hline \multicolumn{6}{|c|}{ Coefficients } \\
\hline & & Estimate & Std. error & $Z$ value & $\operatorname{Pr}(>|z|)$ \\
\hline Intercept & & 1.3834 & 0.4665 & 2.965 & $0.00302 * * *$ \\
\hline Gender: male & & -0.9630 & 0.3598 & -2.676 & $0.00744^{* * *}$ \\
\hline Age 35 to 44 years & & -0.4238 & 0.4533 & -0.935 & 0.34988 \\
\hline Age 45 to 54 years & & -0.6669 & 0.4910 & -1.358 & 0.17444 \\
\hline Age 55 plus years & & -0.2850 & 0.7081 & -0.402 & 0.68735 \\
\hline CU type physics & & -0.6547 & 0.3698 & -1.770 & $0.07665 *$ \\
\hline
\end{tabular}

Note. Dependent variable output facebook_messaging: No $(n=79)$, Yes $(n=85)$.

$* * * * p<0.001,{ }^{* * *} p<0.01,{ }^{*} p<0.1$

The analysis showed that gender was a relevant factor, with a decrease of 0.9630 in the log-odds for male students. Female students were thus statistically more likely to use Facebook messaging in their academic activities (actual figures are females, $66 \%$; males $38 \%$ ).

Table 5 summarizes the analysis of e-books. 
Table 5

Significance of Using e-Books

\begin{tabular}{|c|c|c|c|c|c|}
\hline \multirow[b]{2}{*}{ Variable } & \multicolumn{4}{|c|}{ Analysis of deviance table } & \multirow[b]{2}{*}{$\operatorname{Pr}(>$ chi $)$} \\
\hline & $D f$ & Deviance & Residual Df & Resid. Deviance & \\
\hline NULL & & & 163 & 153.03 & \\
\hline Gender & 1 & 2.5062 & 162 & 150.52 & 0.1134 \\
\hline Age & 3 & 3.1033 & 159 & 147.42 & 0.3760 \\
\hline CU type & 1 & 18.9147 & 158 & 128.50 & $1.367 \mathrm{e}-05^{* * * *}$ \\
\hline \multicolumn{6}{|c|}{ Coefficients } \\
\hline \multirow[b]{2}{*}{ Intercept } & & Estimate & Std. error & $Z$ value & $\operatorname{Pr}(>|z|)$ \\
\hline & & 1.48381 & 0.64661 & 2.295 & $0.0217^{*}$ \\
\hline Gender male & & -0.08186 & 0.50103 & -0.163 & 0.8702 \\
\hline Age 35 to 44 years & & -1.18013 & 0.72549 & -1.627 & 0.1038 \\
\hline Age 45 to 54 years & & -0.75063 & 0.74212 & -1.011 & 0.3118 \\
\hline Age 55 plus years & & -1.39364 & 0.91106 & -1.530 & 0.1261 \\
\hline CU type physics & & 2.10422 & 0.52707 & 3.992 & $6.54 \mathrm{e}-05^{* * * *}$ \\
\hline
\end{tabular}

Note. Dependent variable output e-book_use: No $(n=29)$, Yes $(n=135)$.

$* * * * p<0.001$.

The use of e-books (including PDF) was one situation that stood out in the analysis, as these were more likely to be used in the physics course (log-odds increase of 2.10422). The reason for this was most probably circumstantial, because e-books formed the majority of resources recommended to physics students. In the statistics course, students relied more on videos and printed books.

Finally, Table 6 shows results for the use of Wikipedia.

Table 6

Significance of Using Wikipedia

\begin{tabular}{|c|c|c|c|c|c|}
\hline \multirow[b]{2}{*}{ Variable } & \multicolumn{4}{|c|}{ Analysis of deviance table } & \multirow[b]{2}{*}{$\operatorname{Pr}(>$ chi $)$} \\
\hline & $D f$ & Deviance & Residual Df & Resid. Deviance & \\
\hline NULL & & & 161 & 191.43 & \\
\hline Gender & 1 & 0.9511 & 160 & 190.48 & 0.32945 \\
\hline Age & 3 & 1.1034 & 157 & 189.38 & 0.77625 \\
\hline CU type & 1 & 3.1652 & 156 & 186.21 & $0.07522 *$ \\
\hline \multicolumn{6}{|c|}{ Coefficients } \\
\hline & & Estimate & Std. error & $Z$ value & $\operatorname{Pr}(>|z|)$ \\
\hline Intercept & & 0.1900 & 0.4391 & 0.433 & 0.6652 \\
\hline Gender male & & 0.1219 & 0.3981 & 0.306 & 0.7594 \\
\hline Age 35 to 44 years & & 0.2440 & 0.4694 & 0.520 & 0.6032 \\
\hline Age 45 to 54 years & & 0.5295 & 0.5097 & 1.039 & 0.2989 \\
\hline Age 55 plus years & & 0.6152 & 0.7783 & 0.790 & 0.4293 \\
\hline CU type physics & & 0.7033 & 0.3970 & 1.772 & $0.0765 *$ \\
\hline
\end{tabular}

Note. Dependent variable output wiki_use: No $(n=45)$, Yes $(n=117)$.

${ }^{*} p<0.1$.

Again, the CU type was statistically relevant; physics students used this resource more (log-odds increase of 0.7033) than those in statistics. While the reason for this could not be ascertained from the present data set, it was another hint that the PLE may be shaped by the resources provided by the 
teacher for the CU.

To summarize, the results for analysis number two showed a tendency for course materials to influence students' PLE. Age and gender were not found to be relevant, except in the case of Facebook messaging, which was more likely to be used in academic context by females.

Analysis number three. The third analysis investigated the amount of time spent with courses per week, in the context of time spent in social networking and personal messaging with colleagues. This was done to deepen our understanding of how mobile devices may affect the PLE structure.

Time data was represented as intervals in the questionnaire. This was transformed into interval mean values, and the non-parametric Spearman correlation between mean study time and mean interaction time was evaluated, yielding a value of $+35 \%$. This indicated a mild connection between study time and interaction time. Facebook was considered the most relevant social media, and this is why it was studied separately.

In order to know whether this mild positive correlation was triggered by social media, an ordinal logistic regression was carried out, with study time and interaction time as dependent variables, and use of social media as the independent variable (i.e., Facebook, and all social media). Tables 7 and 8 summarize the results. In these tables, variables are as follows:

- network facebook: use of Facebook. Yes means use.

- network all: use of a social network, of any kind. Yes means use.

- Study time, level (hours/week, self-explanatory):

○ Level 2: 1 to 5 hours

○ Level 3: 6 to 10 hours

○ Level 4: 11 to 15 hours

○ Level 5: more than 15 hours

- Interaction time, level (hours/week, self-explanatory):

○ Level 1: less than 1 hour

○ Level 2: 1 to 5 hours

○ Level 3: 6 to 10 hours

○ Level 4: more than 11 hours

Note that for both study time and interaction time, five levels were defined in the questionnaire, but one level in each set was left empty in the survey, with no responses. 
Table 7

Significance of Study Time, With Social Media as Independent Variables

\begin{tabular}{ccccc}
\hline \multicolumn{5}{c}{ Dependent variable ordering and output } \\
\hline $\begin{array}{c}1 \text { 1 to } 5 \text { hours } \\
62\end{array}$ & 6 to 10 hours & 11 to 15 hours & more than 15 hours \\
21 & 59 & \multicolumn{2}{c}{ Coefficients } \\
\hline \multirow{2}{*}{ Independent variable } & Estimate & Std. error & $Z$ value & $\operatorname{Pr}(>|z|)$ \\
\hline network_facebook Yes & 0.3492 & 0.3181 & 1.098 & 0.272 \\
network_all Yes & 0.2891 & 0.3459 & 0.836 & 0.403
\end{tabular}

Note. Independent variable values network_facebook: No $(n=50)$, Yes $(n=114)$. Independent variable values network_all: No $(n=38)$, Yes $(n=126)$.

The high p-values indicate that the use of Facebook or other social media did not significantly determine study time. In other words, the fact that a student used Facebook or any social media in an academic context did not influence her or his study time.

Table 8

Significance of Interaction Time, With Social Media as Independent Variables

\begin{tabular}{|c|c|c|c|c|}
\hline \multicolumn{5}{|c|}{ Dependent variable ordering and output } \\
\hline less than 1 hour & 1 to 5 hours & \multicolumn{2}{|c|}{6 to 10 hours } & more than 11 hours \\
\hline 94 & 49 & \multicolumn{2}{|c|}{18} & 3 \\
\hline & \multicolumn{4}{|c|}{ Coefficients } \\
\hline Independent variable & Estimate & Std. error & $Z$ value & $\operatorname{Pr}(>|z|)$ \\
\hline network_facebook Yes & 1.2319 & 0.3861 & 3.19 & $0.00142^{* * *}$ \\
\hline network_all Yes & 1.9061 & 0.5108 & 3.732 & $0.00019^{* * * *}$ \\
\hline
\end{tabular}

Note. Independent variable values network_facebook: No $(n=50)$, Yes $(n=114)$. Independent variable values network_all: No $(n=38)$, Yes $(n=126)$.

$* * * * * 0.001,{ }^{* * *} p<0.01$

Table 8 shows how the case was different for interaction time, with positive and highly significant $\mathrm{p}<$ o.1\%) coefficients for both Facebook and all social media. Positive coefficients for Yes mean the Yes answer increased the log-odds of belonging to a higher interval of interaction time $(+1.2319$ [77\%] for Facebook use; +1.9061 [87\%] for all social media). There was thus clear evidence that using social media increased student interaction time, even though it did not necessarily translate into more study time.

\section{Discussion}

Considering all the results, the research questions can now be addressed. With respect to question one, it was evident that students had adopted mobile learning to a high degree (77\%). Concerning what individual factors were significant in the use of mobile learning, clearly there were none. Indeed, statistical evidence showed that all students had embraced mobile learning in a very similar manner, regardless of gender, age, or CU type. Results did not support the view that those students in the older generations may be less likely to use these technologies. 
Concerning question two, to a certain extent, the same conclusion holds for PLEs: students seemed to have created similar learning environments, regardless of gender and age. This somehow contradicts Liaw and Huang (2015) that male learners have less interest in social interaction with other learners and get more involved with apps and technology issues. These authors also stated that female learners showed less interest in technology and a higher intention to share their learning experience and ideas. In our study, no evidence was found of gender difference toward mobile distance learning acceptance, namely in regards to mobile tools and social media. The exception was the use of Facebook Messenger, where females showed a preference. Also, in relation to age, there seemed to be no significant difference, thus contradicting previous claims by Prensky (2001) about digital natives and digital immigrants.

From a decision-making point of view, these results seemed to vindicate a one size fits all teaching approach. This leaves the onus on the institution to understand the value and structure of a student PLE and work towards exploring its potential to the fullest, taking advantage of the anybody, anywhere, anytime possibilities mobile devices provide. It is only the course unit subject, a circumstantial factor, that may dictate some distinction as to the nature of a PLE. For instance, the case of e-books stood out in the analysis, as they were more likely to be used in the physics course. In the statistics course, students relied on videos and printed books. In this context, it would be thought-provoking to test this in a different domain. For example, it would be interesting to know whether the low use of image-sharing tools (empirical value 6.7\%, not shown disaggregated in Table 3) would actually change if a course in fine arts was analyzed instead.

The study also showed that undergraduate students generally perceived mobile technology and digital media as useful, and readily embraced these technologies, with roughly $75 \%$ acceptance. However, there seemed to be a pragmatic approach by students, and while the use of social media did not directly translate to a longer and better study effort, it did lead to more interaction time with colleagues.

Globally, it can be argued that the implementation of PLEs in open and distance education has clear advantages: (a) a student-centric approach, (b) the development of personal knowledge management strategies, and (c) the formation of a self-regulated learning model (Vazquez-Cano, Martín-Monje, \& Castrillo de Larreta-Azelain, 2016). Practical examples include searching for online information, sharing content, selecting resources, developing personal information strategies, and creating content through the use of authoring tools. Nevertheless, there are important issues with respect to the competencies and skills needed to create effective PLEs and the affordances of digital technologies needed to support PLE development (Dabbagh \& Fake, 2017). Accordingly, this study focused on the choice of digital tools that may support self-regulated learning, information management, peer communication, and content aggregation.

The implications for understanding the relationship between students' PLEs and online learning are clear. The former need not be defined as an essential instrument or a crucial model but as contemporary human innovations whose forms and meanings are strategic for education, because these new technologies and resources are part of our society and students have already adopted them.

\section{Conclusion and Future Work}

This article started with a review of the principles underpinning mobile learning and new digital media in the current educational context. Focus was put on how these are enacted in social practices supported 
by contemporary digital habits, and how they may be present in open and distance education.

The study showed that the use of mobile learning and personal learning environments in the physics and statistics courses at Universidade Aberta is transversal to all students, regardless of demographic factors, in part vindicating industrialist approaches to distance learning. Course resources appear to be the most relevant factor which can shape students' personal learning environments, and it was also found that, while social media potentiates online interaction, it does not necessarily increase study time. Evidence also points in the direction of an "always connected" pattern that has taken over the (digital) life of students.

The benefits of the research beyond the two cases can be clearly foreseen; for instance, the ongoing COVID-19 pandemic has shown there is a constant need to implement efficient and cost-effective training to prepare health professionals. Mobile learning is a potential solution to increase the delivery of up-to-date information to health professions, as it offers the prospect of wide access at low cost and flexibility with the portability of mobile devices (Dunleavy, et al., 2019). The pandemic has also highlighted, in a striking and unexpected way, the importance of online learning for educational systems all around the world. In this context, the findings of this article can help provide more efficient ways to implement learning by connecting current social needs to learners' mobile PLEs, particularly when flexibility of time and space are of utmost importance.

Further studies at the Portuguese Open University will address a larger and more balanced sample of students across more course units. We will reach for a wider range of fields and subjects, overcoming small sample sizes, and further test the hypothesis of whether a PLE may be sensitive to resources made available in specific domains, including arts, humanities, and life sciences. 


\section{References}

Alzen, J. L., Langdon, L. S., \& Otero, V. K. (2018). A logistic regression investigation of the relationship between the learning assistant model and failure rates in introductory STEM courses. International Journal of STEM Education, 56(5). https://doi.org/10.1186/s40594018-0152-1

Attwell, G., Bimrose, J., \& Brown, A. (2008). Maturing learning: Mashup personal learning environments. Proceedings of 1st Workshop MUPPLE'O8, Maastricht, Netherlands. Retrieved from http://dspace.ou.nl/bitstream/1820/1501/1/muppleo8 dspace.pdf\#page=84

Bidarra, J., Figueiredo, M., \& Natálio, C. (2015). Interactive design and gamification of e-books for mobile and contextual learning. International Journal of Interactive Mobile Technologies, 9(3). https://doi.org/10.3991/ijim.v9i3.4421

Brown, T. H., \& Mbati, L. S. (2015). Mobile learning: Moving past the myths and embracing the opportunities. The International Review of Research in Open and Distributed Learning, 16(2). https://doi.org/10.19173/irrodl.v16i2.2071

Chen, W-P, Millard, D., \& Wills, G. (2008) Mobile VLE vs. mobile PLE: How informal is mobile learning? Proceedings of mLearn 2008 Conference. Retrieved from https://eprints.soton.ac.uk/266158/1/InformalMobileLearning_modification_final_0718.pdf

Cochrane, T. D. (2010). Exploring mobile learning success factors. Research in Learning Technology, 18(2). https://doi.org/10.1080/09687769.2010.494718

Cross, S., Sharples, M., Healing, G., \& Ellis, J. (2019). Distance learners' use of handheld technologies. The International Review of Research in Open and Distributed Learning, 20(2). https://doi.org/10.19173/irrodl.v20i2.4040

Dabbagh, N., \& Fake, H. (2017). College students' perceptions of personal learning environments through the lens of digital tools, processes and spaces, Journal of New Approaches in Educational Research, 6(1). https://doi.org/10.7821/NAER.2017.1.215

Dabbagh, N., \& Kitsantas, A. (2012). Personal learning environments, social media, and self-regulated learning: A natural formula for connecting formal and informal learning. The Internet and Higher Education, 15(1), 3-8. https://doi.org/10.1016/j.iheduc.2011.06.002

Dunleavy, G., Nikolaou, C. K., Nifakos, S., Atun, R., Law, G. C. Y., \& Tudor Car, L. (2019). Mobile digital education for health professions: Systematic review and meta-analysis by the digital health education collaboration, Journal of Medical Internet Research, 21(2). https://doi.org/10.2196/12937

Feng, S., Wong, Y. K., Wong, L. Y., \& Hossain, L. (2019). The Internet and Facebook usage on academic distraction of college students. Computers \& Education, 134, 41-49. https://doi.org/10.1016/j.compedu.2019.02.005

Fiedler, S. H., \& Väljataga, T. (2013). Personal learning environments: Concept or technology? In M. Thomas (Ed.), Technologies, innovation, and change in personal and virtual learning 
environments (pp. 166-176). Hershey, PA: IGI Global. https://doi.org/10.4018/978-1-46662467-2.cho14

García-Peñalvo, F. J., \& Conde, M. Á. (2015). The impact of a mobile personal learning environment in different educational contexts. Universal Access in the Information Society, 14(3), 375387. https://doi.org/10.1007/s10209-014-0366-z

Gómez-Ramirez, I., Valencia-Arias, A., \& Duque, L. (2019). Approach to m-learning acceptance among university students. The International Review of Research in Open and Distributed Learning, 2O(3). https://doi.org/10.19173/irrodl.v20i4.4061

Johnson, M., \& Liber, O. (2008). The personal learning environment and the human condition: From theory to teaching practice. Interactive Learning Environments, 16(1), 3-15. https://doi.org/10.1080/10494820701772652

Kearney, C. (2016). Efforts to increase students' interest in pursuing mathematics, science and technology studies and careers (Report on national measures taken by 30 countries: 2015). Brussels, Belgium: European Schoolnet.

Kukulska-Hulme, A. (2007). Mobile usability in educational context: What have we learnt? International Review of Research in Open and Distributed Learning, 8(2). https://doi.org/10.19173/irrodl.v8i2.356

Krull, G., \& Duart, J. M. (2017). Research trends in mobile learning in higher education: A systematic review of articles (2011-2015). The International Review of Research in Open and Distributed Learning, 18(7). https://doi.org/10.19173/irrodl.v18i7.2893

Labach, J. E. (2011). The impact of web-based instruction on faculty in higher education institutions: New directions for research. International Journal of Business and Social Science, 2(24), 4957. Retrieved from http://ijbssnet.com/view.php?u=http://ijbssnet.com/journals/Vol 2 No 24 Special Issue December 2011/5.pdf

Lai, J. W. M., \& Bower, M. (2019). How is the use of technology in education evaluated? A systematic review. Computers \& Education, 133, 27-42. https://doi.org/10.1016/j.compedu.2019.01.010

Liaw, S.-S., \& Huang, H.-M. (2015). How factors of personal attitudes and learning environments affect gender difference toward mobile learning acceptance. The International Review of Research in Open and Distributed Learning, 16(4). https://doi.org/10.19173/irrodl.v16i4.2355

ANACOM. (2019). ANACOM Report - Mobile Service 2018. Retrieved from https://www.anacom.pt/streaming/SM_4T2018.pdf?contentId=1472413\&field=ATTACHED -FILE

Niu, L. (2020). A review of the application of logistic regression in educational research: Common issues, implications, and suggestions. Educational Review, 72(1), 41-67.

https://doi.org/10.1080/00131911.2018.1483892 
Park, Y. (2011). A pedagogical framework for mobile learning: Categorizing educational applications of mobile technologies into four types. The International Review of Research in Open and Distributed Learning, 12(1). https://doi.org/10.19173/irrodl.v12i2.791

Pereira, A., Quintas-Mendes, A., Morgado, L., Amante, L., \& Bidarra, J. (2008). Universidade Aberta's pedagogical model for distance education: A university for the future. Lisbon, Portugal: Universidade Aberta. Retrieved from http://hdl.handle.net/10400.2/2388

Prensky, M. (2001). Digital natives, digital immigrants, part 1. On the Horizon, 9(5), 1-6.

Prince, M. (2004). Does active learning work? A review of the research. Journal of Engineering Education, 93(3), 223-231. https://doi.org/10.1002/j.2168-9830.2004.tbo0809.x

Schmid, R., \& Petko, D. (2019). Does the use of educational technology in personalized learning environments correlate with self-reported digital skills and beliefs of secondary-school students? Computers \& Education, 136, 75-86. https://doi.org/10.1016/j.compedu.2019.03.006

Sharples, M., Corlett, D., \& Westmancott, O. (2002). The design and implementation of a mobile learning resource. Personal and Ubiquitous Computing, 6(3), 220-234. https://doi.org/10.1007/s007790200021

Sung, Y-T., Chang, K-E., \& Liu, T-C. (2016). The effects of integrating mobile devices with teaching and learning on students' learning performance: A meta-analysis and research synthesis. Computers \& Education, 94, 252-275. https://doi.org/10.1016/j.compedu.2015.11.008

Thomas, L., Orme, E., \& Kerrigan, F. (2020). Student loneliness: The role of social media through life transitions. Computers \& Education, 146, 103754. https://doi.org/10.1016/j.compedu.2019.103754

Traxel, J. (2009). Learning in a mobile age. International Journal of Mobile and Blended Learning, 1(1). https://doi.org/10.4018/jmbl.2009010101

Vainio, T., \& Walsh, T. (2017). Learning maths with mobiles: Cross-cultural design of technology with experiences in South-Africa and Finland. In I. Management Association (Ed.), Blended learning: Concepts, methodologies, tools, and applications (pp. 741-759). Hershey, PA: IGI Global. doi:10.4018/978-1-5225-0783-3.cho37

van Harmelen, M. (2008). Design trajectories: Four experiments in PLE implementation. Interactive Learning Environments, 16(1), 35-46. https://doi.org/10.1080/10494820701772686

Vazquez-Cano E., Martín-Monje, E., \& Castrillo de Larreta-Azelain, M. D. (2016). Analysis of PLEs' implementation under OER design as a productive teaching-learning strategy in higher education. A case study at Universidad Nacional de Educación a Distancia. Digital Education Review, 29, 62-85. Retrieved from http://greav.ub.edu/der

Wilson, S. (2008). Patterns of personal learning environments. Interactive Learning Environments, 16(1), 17-34. https://doi.org/10.1080/10494820701772660 
Wong, L.-H., \& Looi, C. K. (2011). What seams do we remove in mobile assisted seamless learning? A critical review of the literature. Computers and Education, 57(4), 2364-2381.

https://doi.org/10.1016/j.compedu.2011.06.007

Athabasca

University

(c) $(\mathrm{C}$ 